\title{
Formative experience
}

\section{John Kay, Gwyn Groves, Rick Greenough, Bin Wu and Tim Baines describe the pioneering approach to industrial experience given to postgraduates at Cranfield University}

In facing the challenge of world competition, successful industrial businesses are those that recognise the strategic role and importance of their manufacturing function. These companies need highly skilled, knowledgeable and innovative individuals who can design and manage worldclass manufacturing businesses. The challenge to universities worldwide, and especially to those in a first-world industrialised country such as the UK, is to provide an educational process than can deliver such capable employees. This article describes how Cranfield University is approaching this challenge in its manufacturing masters' courses.

Cranfield University specialises in research and education relevant to industry. It offers a wide range of quality postgraduate education, along with an expanding range of short courses, and applied research. A distinctive feature of many Cranfield manufacturing MSc courses are the industrially based group projects. This feature is designed to ensure that students develop the advanced skills and experience needed by industry.

The group project approach is a very prominent aspect of the Cranfield educational process. It is well established, providing a focal point for interactions with industry. However, this educational mechanism is rarely published to the wider world. This article has been prepared to provide an insight into the group project process at CranGeld, with the aim of raising awareness of this educational process to industrialists, educators and students alike.

The MSc course in 'Engineering and management of manufacturing systems' at Cranfield was designed in response to manufacturing industry's increasing need for highly capable and experienced people. It aims to develop the trained and qualified individuals demanded by today's manufacturers: able to make an immediate contribution to a company's manufacturing performance and operation, and to progress into senior management positions. The course may be studied full-time or part-time. The aims of the course are met by:

- a series of ten carefully integrated and structured one-week modules, comprising lectures, laboratories and tutorials, plus an induction module

- a major individual thesis project

- a unique industrially sponsored group project.

For the group project, the students, working in teams, are given the overall responsibility for an industrially sponsored consultancy-style project, with a three month timescale and a fixed project. The teams produce a comprehensive final report, software where appropriate, and make a public presentation to visitors from industry. Each project has an academic supervisor to provide guidance and to monitor and assess the performance of each student.

For the 1997/98 academic year, 27 full-time students followed this course at Cranfield. This group was divided into three teams to undertake group projects sponsored by Ernst \& Young, Ford and Stantons Timber Services. In June an audience of 160 came to listen to the three student teams make their presentations on projects.

\section{1: The impact of ERP}

Ernst \&Young asked the project team to investigate implementations of enterprise resource planning in the manufacturing sector. The overall aim was to collect and analyse information to assist Ernst \&Young in developing leading practice guidelines for the implementation and optimisation of ERP systems.

ERP systems can be viewed as the next generation to manufacturing resource planning (MRP II). Many ERP users are not familiar with the acronym, and tend to refer to their systems by the name of the software vendor, such as SAP, Baan, Oracle or Peoplesoft. These computer systems integrate all the business processes, and then become the 
means to support and speed the entire order-fulfilment process. However, the complexity of the systems requires a very well structured approach for their implementation and optimisation.

The ERP marketplace has seen significant growth over the last few years, with many current implementations having been driven mainly by the millennium compliance issue. In the USA alone, revenues for the industry grew by $34 \%$ to $\$ 5.21$ billion in 1996. Industry analyses are forecasting growth rates of $30 \%$ or more for at least the next five years.

ERP projects may last several years from decision to implementation. However, timescales will vary from company to company depending upon many factors. Fig. 1 shows the main stages usually followed in a typical ERP implementation.

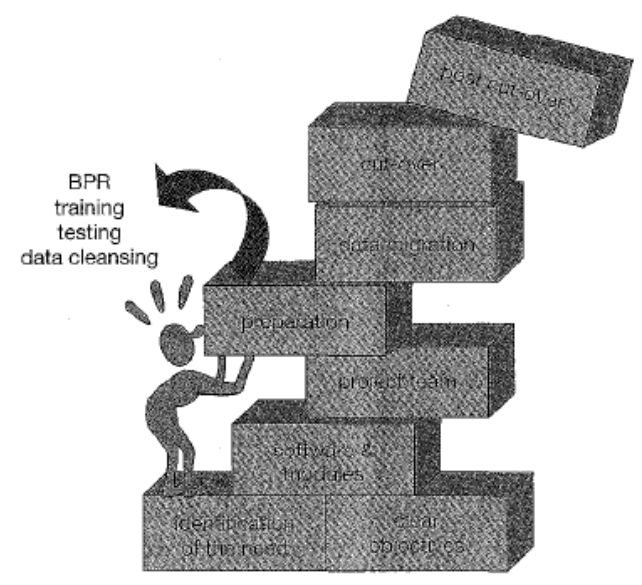

Fig. 1 The ERP life cycle

A typical implementation lifecycle starts with identification of the need for an ERP system, for which clear objectives should be established, followed by the software and module selection process. Next, the project team has to be set up. Then comes preparation, which encompasses business process re-engineering, training, testing and data cleansing. Typically these take place in parallel. The next stage is data migration-the transfer of data from the old system to the new system, leading to the cut over to the new. Support is also required after this stage.

Ernst \& Young consultants worked in close collaboration with the team of nine students and their supervisor throughout the three month project. The project focused mainly on medium-to-large UK manufacturing companies. In order to focus on these companies effectively within the timescales given, the nine team members divided into three sub-groups, with responsibility for two sectors each: group 1 took aerospace and defence and automotive, group 2 pharmaceuticals and consumer products, and group 3 electronics and system implementers.

The group chose to investigate aspects of ERP implementation by conducting a series of semi-structured interviews at companies within each sector. Background information was gathered by interviewing Ernst \& Young consultants, and from 'desk research'. A questionnaire was designed and then tested through pilot interviews with two companies. The next step was to identify companies that had completed implementation, or were in the process of implementation.

Ernst \& Young set a target of 45 companies to be interviewed. Contacts were made via telephone rather than by mail, in order to gain a quicker response. Companies willing to participate were fixed a project briefing and a code of conduct, covering issues of confidentiality, use of information and feedback. Over 300 companies were contacted, and after a great deal of effort and rejection, 50 sets of interviews throughout the UK were secured. It was estimated that the group had driven over $20000 \mathrm{~km}$ to complete all the interviews.

The data then had to be analysed. The questionnaire was created in a database format, to allow an easy and consistent way to compare different company results, while keeping all the data in the same place. The 50 companies interviewed also provided the group with more than 2000 qualitative excerpts that needed analysing. To 
make this more manageable, the group decided to identify threads or trends within the information. This provided the team with key areas in which to search for commonalities and differences in each sector. A technique called mind mapping was used to visually identify clusters and trends within the qualitative information (Fig. 2).

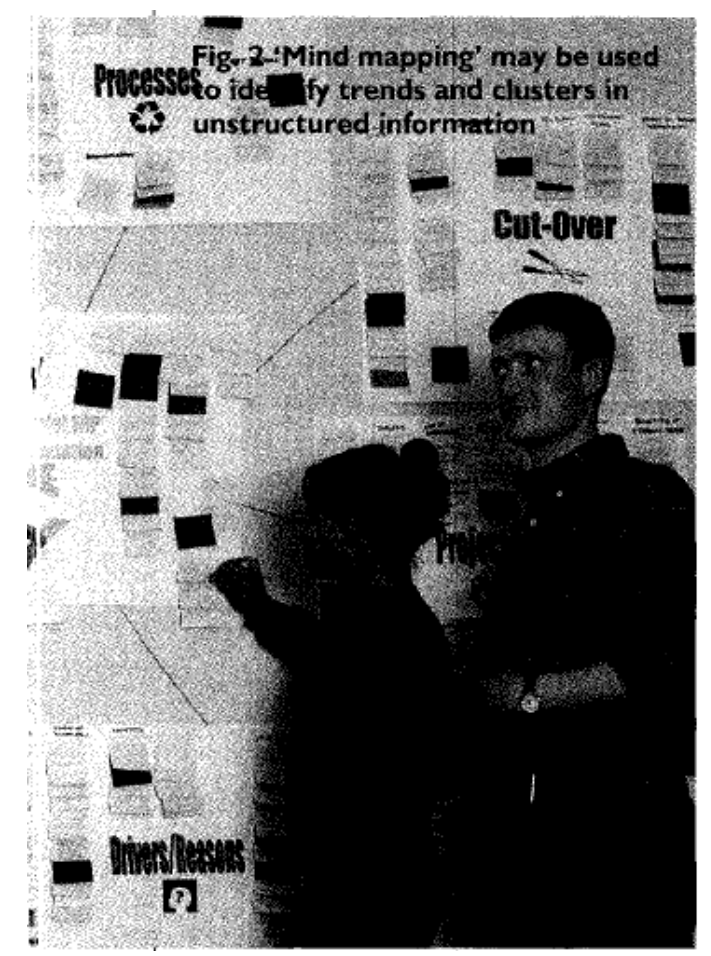

The team's analysis revealed that successful ERE' implementation is dependent on a small set of key factors, namely:

- clearly defined reasons for implementation

- commitment from all levels, from top management to end users

- a cross-functional project team using the very best shlls and knowledge

- thorough project planning with realistic time estimates

- structured software selection process

- re-engineering of processes, to minimise software customisation

- appropriate amount and timing of end user training

- testing of the ERP system and interfaces before cut over method

- choice of the appropriate cut over

- use of experienced outside assistance.

Ernst \& Young received a comprehensive written report, and summary reports were also provided for each of the participant companies.

What about Ernst Young's perspective? Ernst \& Young is a global consultancy employing about 350000 management consultants worldwide. About one-third of its work is in manufacturing industry. lan Batey, from Ernst \& Young, offered the following comments about the student work and what they achieved:

'The teams have learned a lot. They talk very coherently about ERP and the whole subject area, what some people in manufacturing are doing there, some of the good practices, and some of the bad. They had to form a team to do this work and they also had to deal with 50 sets of potentially different styles and personalities of very busy people in manufacturing organisations. All of that personal development and learning has got to be good for their future.

'In terms of the project itself, just think about what they did. They formed a team, did a lot of background research, and had detailed interviews with myself and the other members of the Ernst \&Young team. They constructed a survey for their collection mechanism, identified targets for interviews, made appointments from 50 sets of busy 
individuals-and that is no mean achievement in itself. They carried out the interviews, designed, built and populated a database to analyse the data and then finally presented this entertaining response to us today All of that within three months, an excellent achievement.'

\section{2: Simulation and measurement}

Ford In-line Engine Operations leads the automotive world in the use of a type of discrete-event-simulation tool to model automated transfer lines. Writing and testing these models is a demanding task, and the results of the simulation studies often have to be carefully explained to those unfamiliar with the software. In association with Ford, Cranfield University launched a project in which ten students modelled several new lines, which are currently being designed to manufacture a new Ford engine.

The location of the engine plant that has been modelled, along with the precise engine design that will be produced, is confidential and cannot be discussed in detail here. However, as a general overview, the plant consists of six production lines that produce the main components of an engine. These lines are the cylinder head line, the cylinder block line, the connecting rod line, the camshaft line, the crankshaft line, and the assembly line.

At Ford, engines are assembled using transfer lines. For each transfer line, there are many different machines which are linked by conveyors, and hence there are many parameters which can vary.

Ford uses Witness from Lanner Group for engine-line simulation, and since this is also the tool with which the Cranfield students are familiar, it was used in the project. To model the Ford production system accurately, the students have worked closely with several different departments within Ford to obtain the necessary information. This interactive process took place both at Ford and Cranfield; as Fig. 3 shows, the project gave a good opportunity for Cranfield students to work closely with personnel from both Ford and Lanner.

The engine plant that was modelled is made up of five machining lines for the crank, the connecting rods, the block, the cylinder head and the camshafts, as well as the assembly line. The students built, tested and analysed six simulation models of these complex lines during the project. Fig. 3 shows a schematic version of the main plant simulation model.

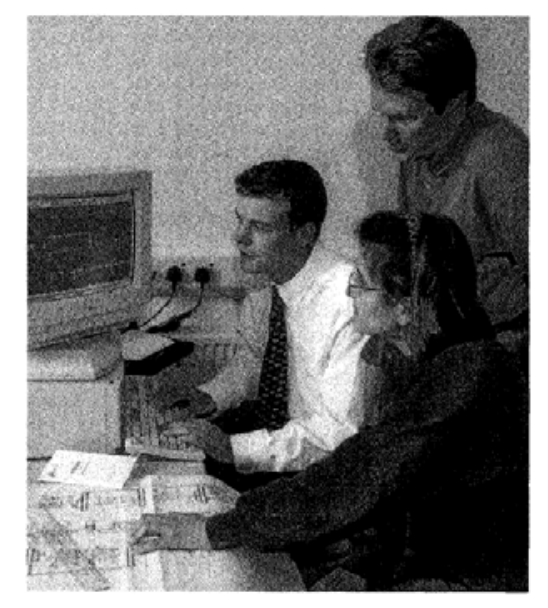

Fig. 3 Students work closely with experienced engineers on real problems

The outputs from the simulation models have been and will be used by a large number of Ford staff, and for this reason reports are generated in the form of Excel spreadsheets. Ford's own performance measures are used in the spreadsheets to report the behaviour of the models, such as the capacity of the new lines and how many people are needed to operate them. Ford engineers need to know the effects of design parameters, such as machine layout, conveyor speed, etc., on the critical performance measures. To speed the construction of these models and to aid such work in the future, the students have also produced simulation productivity tools, such as a register of simulation models. 
Experimental results from the simulation exercise have allowed Ford to spot potential problems with the new factory at the design stage, leading to significant cost savings. Findings on bottleneck location and severity, work in progress levels, production levels and throughput times have helped Ford with the design and engineering of the new engine plant. Ford engineers asked the students detailed questions about transfer line performance, which were answered and illustrated in presentations.

Indeed, a particular advantage to Ford of using a group of students in this way was that the volume of work carried out by the students allowed the simulation process to keep up with the rate of progress being made on the design of their new factory. This in turn allowed closer and more detailed analysis of the production lines as they were being designed. Again we cannot give specific data relating to the performance of the proposed plant. However, in general terms, simulation models helped Ford to make the following improvements:

- By optimising the location of buffers, the output of the cylinder block line was increased by $2 \%$.

- It was shown that the number of pallets on the assembly line could be reduced by $16 \%$ and the dock-to-dock time by $12 \%$. The number of test bays could be reduced, increasing test bay usage by $4 \%$.

- Simulation also illustrated problems with the complex logic of gantry material handling devices on the cam and crank lines and allowed different solutions to be compared.

- On the computing rod line, simulation showed how machine cycle times could be increased by $10 \%$ without reducing output. This should lead to greater reliability. A conveyor redesign issue was highlighted through simulation which showed how work-in-progress (WIP) could be reduced by $20 \%$.

This was the second group project Ford has sponsored recently John Ladbrook from Ford gave his verdict about work with Cranfield:

'These projects are really like gold dust to me, and the time and the effort that I put into them really does repay itself. The outcomes from both of the projects I have had sponsored have far exceeded my expectations.

'Three months ago, when we started the project, I came in and outlined the project to the students and it was great to see the look on their faces. They were sitting there thinking "what have we let ourselves in for? How are we going to build 6 models, run experiments, and present the results?" Here we are three months later, they have done all the work-and not only done it, but done it exceedingly well, and that's my opinion after being involved in simulation for 15 years. During that time they have still surprised me with some very innovative modelling techniques which was great to see.

'As part of the project the students had to present the models to the Ford Motor Company team, which is not an audience that I like to present to. They are very critical and they do have a good understandmg of simulation. I was concerned when the students went in but they really have done an excellent job and dare I say it was every bit as good as I could have done.'

\section{Activity-based costing}

Stantons Timber Services, owned by Finnforest and a division of Interpan Timber Ltd., is a part of the Metsälitto group. As a result of significant investment in new technology over the last 10 years, it is today one of the most advanced timber processing companies in the world. State of the art facilities and fully integrated production lines enable the company to meet over $30 \%$ of the UK demand for machined softwoods, both in the commercial and DIY sectors.

As an attempt to help increase the company's overall efficiency, this project was focused on the costing aspect of the organisation at the company's Boston site in the UK. The Cranfield team investigated the company's operational functions and developed a framework for a costing/planning model, based on activity based costing (ABC), which can track the cost of each product unit through the manufacturing system, and help managers to schedule production more efficiently. 
During the project period, the company and the team worked closely to specify the structure and functionality of the production planning and control model. A spreadsheet model was designed incorporating the concepts of $A B C$ and finite-production scheduling. This model was configured to facilitate the evaluation of line setup times, different production schedules and batch sizes.

This assessment is measured in terms of the time required by the production facilities and the cost of production and raw material required. Therefore, in response to a particular set of such inputs, the model is capable of producing the following outputs:

- Time and cost of every production batch. The user can see how long it takes to produce a batch, when it should be ready, and the relative cost of the batch.

- Time and cost of a production sequence. This helps to plan the best possible production sequence over a period of time.

- Performance index. For each production sequence, the model calculates a performance index for each production line based on its practical capacity. This helps the user to identify the best possible production plan within practical constraints.

- Graphical output. The model also provides the user with a set of graphs to give a more visual tool for analysis.

In parallel with the model building, all of the work done was carefully recorded The conceptual structure of the model, the original data, the formulas developed and the programme coding have all been properly documented, in the hope of making the application and updating of the model easier.

Explaining the reason for choosing the Cranfield team for the work, Ole Salvén, the managing director of Stantons, said. 'It was kind of intriguing and exciting to think that we had this pool of talent at our disposal. Regarding the project execution and results, having refined the project scope, it is absolutely clear that we have done a magnificent job. And when a Nordic person uses a superlative, that means it is really good! The attention to detail, the way they presented it, and how they went through all the specifications of the production lines, a very very good job. I must say that I am overjoyed with the result.'

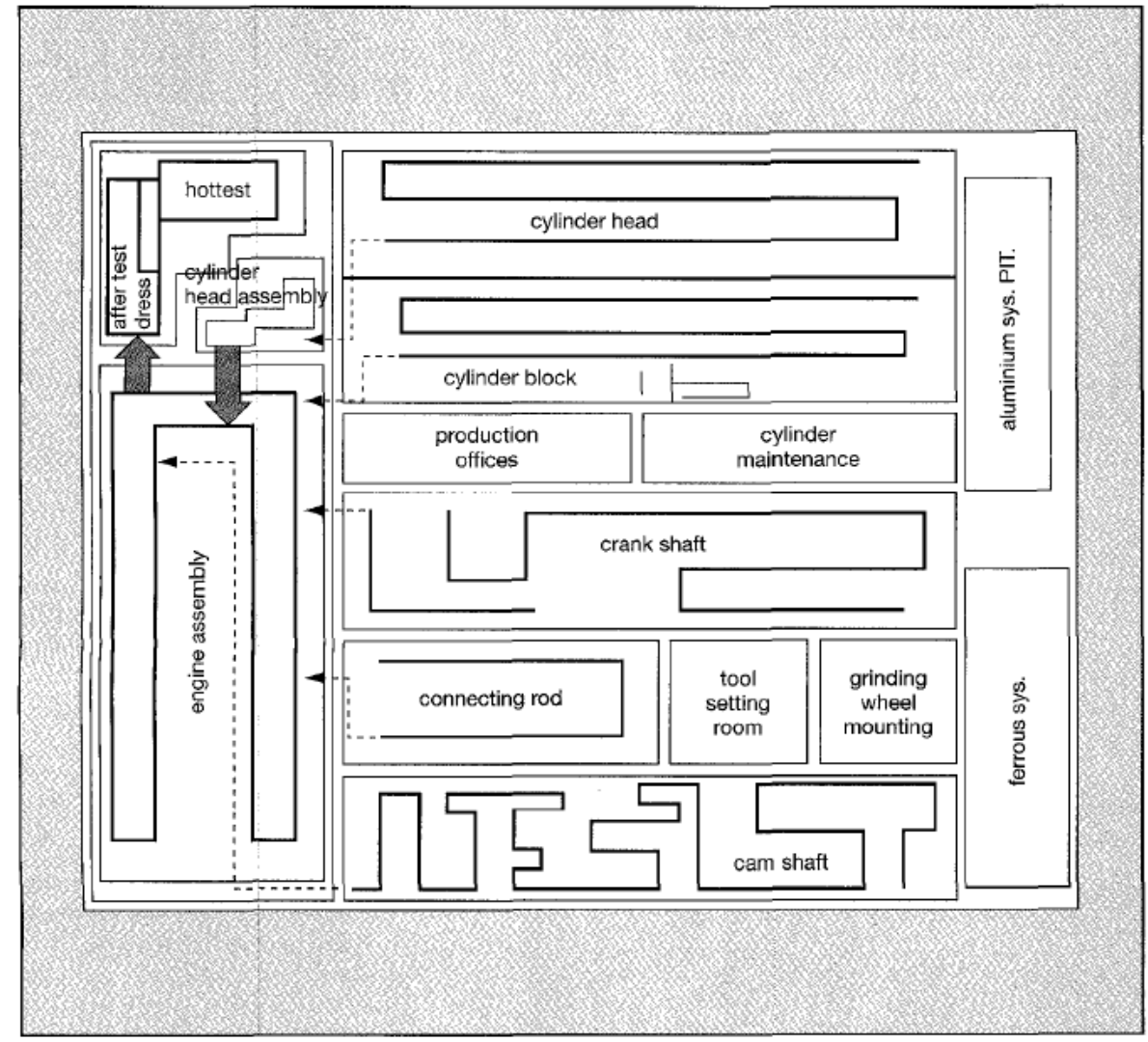

Fig. 4 A schematic illustration of the Ford Engine Plant modelled Effectiveness 
The group project approach to learning is well established at Cranfield, being an integral part of the manufacturing systems course for nearly 20 years. Experience has showed that this education process is effective in providing people with the right skills and knowledge for industry. Graduates are employed in a wide range of manufacturing and associated roles within companies throughout the world. The practical nature of the course, and the emphasis on industrially based project work, creates the confident and assured approach that companies find very desirable in their employees.

However, this approach to education is resource intensive, and is only possible where industrial sponsors provide significant sponsorship. It is also essential that real industrial problems are addressed. Furthermore, to attract such sponsors, the students have to be capable of adding real value to the project, and hence this approach is particularly well suited to postgraduate level education.

A critical factor in the success of the group project work is the length of time over which a project is conducted, and this may vary to suit the particular focus of each programme. The 'Engineering \& management of manufacturing system' MSc places a three month limit on project duration, which means that the group project team has to perform from the start. Similarly, the sponsoring company also has to respond quickly during this period.

Indeed, tackling an ambitious project over a short time period can place extreme stress on staff and students alike, yet it is this very experience that drives the development of character and skills that are in such demand by industry. 